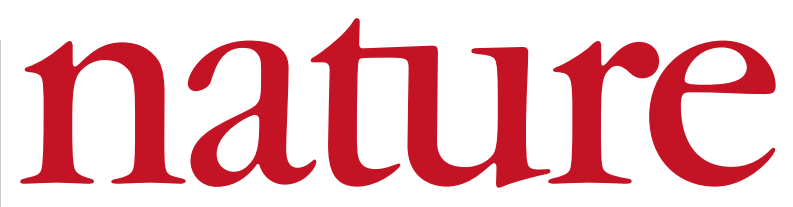

27 November 2003 Volume 426 Issue no 6965

Facing up to endangered apes

A United Nations-sponsored meeting in Paris this week will indicate whether humanity has the wherewithal to save our closest cousins in the animal kingdom from extinction.

A s any orang-utan who has looked a human straight in the eyes will know, we have something, well, quite orang-utanish about us. Evidence increasingly points to the great apes orang-utans, gorillas and chimpanzees - having a range of 'human' attributes, such as culture, emotion and complex social interaction, not to mention being highly intelligent and a marvel to watch. If we allow the great apes to go extinct, we will create a missing link in the understanding of who we are and where we came from.

But all three genera of great apes are climbing up the scale of extinction risk, with most populations somewhere between 'endangered' and 'critically endangered'. Behind these tags lies the stark reality that numbers are now dropping precipitously. Unless we act soon, every species of great ape will be extinct in the wild in our childrens' lifetimes.

Gorillas live in ten African countries, orang-utans on the islands of Borneo and Sumatra in Indonesia and East Malaysia, and chimpanzees in 21 countries in Africa. But by 2030, just 10\% of virgin habitat for apes in Africa will still exist, and less than $1 \%$ of it for orang-utans.

Destruction of forests is one cause of the decline; hunting for bushmeat or for the live-animal trade is another. And apes have the misfortune to tend to live in war zones, which hampers conservation efforts. Even in remote areas, away from their number-one enemy - us - apes are being wiped out by the Ebola virus (see Nature 422, 551;2003).

In Paris on 26-28 November, representatives of African and Asian states with ape populations are due to meet with scientists under the auspices of the United Nations' Great Apes Survival Project (GRASP). They hope to thrash out a conservation strategy for the great apes, endorsed by everyone with an interest in their survival.

There is certainly no shortage of interest. Numerous organizations exist to save them. On paper, great apes are already protected by law in every country they inhabit, national action plans exist, and the international ape trade is banned. But the numbers just keep dwindling.

The meeting's organizers acknowledge that action is needed. Existing conservation efforts are inadequately coordinated and too piecemeal, and projects are set up as funds become available, rather than as part of an overall strategy. The meeting will attempt to expand the ability of GRASP to oversee and implement such a strategy.

Another proposal is to create an International Great Ape Commission - recognized by established zoological bodies - to bring together the countries affected, donors, scientists and non-governmental organizations, to generate publicity for the cause, and to develop common plans and more rigorous systems for evaluating best practice in conservation approaches.

The attention that the meeting will bring to the issue is welcome. The United Nations reckons that a serious effort to lift the immediate extinction threat hanging over great ape populations would cost some US $\$ 25$ million. It would be ironic if, just when humans have sequenced our own genome, we allowed a group of species that share almost $99 \%$ of it to go extinct.

\title{
Eastern promise
}

Untapped scientific potential to the east offers short-term challenges for the European Union, but will strengthen it in the end.

T he European Commission's latest report on science, technology and innovation, published on 25 November, makes for a sobering read. It shows not only that the 15 European Union (EU) countries have made little progress towards their avowed goal of increasing their expenditure on research and development (R\&D), but that the gap in such spending between the EU and the United States is actually widening.

However, a close reading of the document suggests at least one route forward as Europe struggles to strengthen its research base the largely untapped human potential of the nations of eastern Europe, most of which are now in the process of joining the EU.

A goal of boosting R\&D spending to 3\% of the economy by 2010 was publicly proclaimed by Europe's leaders at the Barcelona EU summit in 2002, but now seems to be less realistic than ever. Any prospect of boosting this investment has been choked by Europe's recent economic weakness. In 2001, the most recent year for which a reliable comparison is available, for example, industry and government in the EU 2001 spent $€ 141$ billion (US $\$ 165$ billion) less on R\&D than did the United States - almost twice the gap that existed in 1999.

It is sometimes said that EU enlargement, under which ten eastern and central European nations will join the union next May, will aggravate the discrepancy. But this month's report suggests that in the longer term, the dynamics and favourable demography of the ten countries might provide a badly needed boost for European science.

Currently, their total R\&D expenditures account for just $2 \%$ of the EU's $€ 178$-billion total annual expenditure. But their growth potential is considerable. Estonia, Hungary, Lithuania, Slovenia and Latvia, for example, are already among the top-ranked economies in the world in terms of the growth of their research activities. And the first results of their participation in the EU's Sixth Framework Programme indicate growing competitiveness in their research capabilities.

The European Commission needs to step in to support the east's budding capabilities, particularly in promising areas such as computer science. In the short term, a change in the rules to allow universities and research laboratories to benefit from so-called 'structural' funds, directed at infrastructure in poor regions, would help.

In the medium term, EU policies should change to accommodate the fact that the main strengths of countries such as the Czech Republic, Poland and Hungary lie not in technology development, where existing policy has its focus, but in basic research. Putting more money into this - through a proposed European Research Council, for example — would help these countries to assert their potential.

As the report makes clear, these countries have great human potential. Their populations are well educated, particularly in science and mathematics. In the long term, Europe must exploit this talent if it is to be globally competitive in science, technology and innovation. 